\title{
Intestinal permeability in patients with Crohn's disease and ulcerative colitis and their first degree relatives
}

\author{
P Munkholm, E Langholz, D Hollander, K Thornberg, M Orholm, K D Katz, V Binder
}

\begin{abstract}
Increased intestinal permeability in patients with Crohn's disease and their first degree relatives has been proposed as an aetiological factor. The nine hour overnight urinary excretion of polyethyleneglycol-400 (PEG-400) and three inert sugars (lactulose, 1-rhamnose, and mannitol) was used to test the permeation in 47 patients with Crohn's disease of whom 18 had at least one first degree relative with inflammatory bowel disease (2BD) and 52 patients with ulcerative colitis of whom 16 had at least one first degree relative with IBD. A total of 17 first degree relatives with IBD and 56 healthy first degree relatives were included. Thirty one healthy subjects not related to patients with IBD served as controls. No significant differences in PEG-400 permeation were found between the groups of patients, relatives, and controls, or between diseased and healthy relatives. The permeability to lactulose, rhamnose, and mannitol similarly did not differ between the three groups. This study challenges the previously reported findings of increased PEG-400 permeation in patients with Crohn's disease and in their healthy and diseased first degree relatives. There was no increase in permeability in a similar group of ulcerative colitis patients and their families. (Gut 1994; 35: 68-72)
\end{abstract}

There has been great interest in the hypothesis of increased intestinal permeability as a pathogenetic factor in Crohn's disease. Evidence has been found for a genetic predisposition to Crohn's disease. ${ }^{1-3}$ A 10 -fold increased risk of inflammatory bowel disease among first degree relatives of patients with ulcerative colitis and Crohn's disease has recently been found in a regional epidemiological study. ${ }^{4}$ Therefore further permeability studies of healthy and diseased relatives of inflammatory bowel disease patients were needed to clarify the possible connection between permeability abnormalities and genetic predisposition to inflammatory bowel disease.

Excretion of the hydrofilic polyethyleneglycol-400 (PEG-400) in urine after oral ingestion has been suggested as a possible marker of a genetically determined increased permeability of the gut wall. An increase in PEG-400 permeation in Crohn's disease patients and their first degree healthy relatives compared with healthy controls was found in a previous study, ${ }^{5}$ whereas two other studies could not confirm these findings. ${ }^{67}$ Absorption of inert sugars such as lactulose (L), rhamnose $(\mathrm{R})$, and mannitol $(\mathrm{M})$ was subse- quently tested by Hollander's group and permeability abnormalities could not be found in the relatives but patients with inflammatory bowel diseases had increased lactulose permeation compared with the control group. ${ }^{8}$ Two studies have recently shown, however, increased L/M ratio in first degree healthy relatives compared with Crohn's disease patients. ${ }^{910}$

The aims of this study have been firstly, to elucidate whether previously reported results of increased permeability in Crohn's disease patients and their healthy relatives could be confirmed in a larger group of patients; secondly, to extend the permeability analysis to inflammatory bowel disease patients with known familial occurrence and their diseased and healthy first degree relatives to evaluate possible differences in absorption of the PEG-400 and the three insert sugars, lactulose, rhamnose, and mannitol in these families.

\section{Patients and methods}

\section{SELECTION OF THE PATIENTS}

Patients with known familial occurrence of inflammatory bowel disease were included in the study, and encouraged to contact all their first degree relatives and propose their participation in the study. Other patients were included consecutively from the outpatient clinic in Copenhagen County.

All patients had stopped taking non-steroidal anti-inflammatory drugs (NSAIDs) for more than 30 days. Seven patients on topical steroids and six on low dose systemic steroids were included. Twenty five Crohn's disease patients and 25 ulcerative colitis patients were receiving maintenance treatment with sulphasalazine or 5-aminosalicylic acid (5-ASA).

The Crohn's disease activity index" and activity score of ulcerative colitis, ${ }^{12}$ the extent of the disease at diagnosis, age, sex, duration of disease, and length of resection were recorded. Active Crohn's disease was considered when the index was $>150$ and active ulcerative colitis was considered when scoring was $>$ II.

\section{Crohn's disease}

Forty seven patients with Crohn's disease were included, F/M: 30/17, median age: 38 years (18-73). The median duration of disease was six years $(1-37)$

Twenty nine of the patients had had a previous operation, with a median resection length of $55 \mathrm{~cm}(10-130 \mathrm{~cm}) ; 21(72 \%)$ with ileocaecal resection, three $(10 \%)$ with small bowel resec- 
tion, and four (14\%) with total or subtotal colectomy. In one patient the type of operation was not known.

Relatives of patients with Crohn's disease

Eighteen Crohn's disease patients had familial occurrence of inflammatory bowel disease. Thirty nine first degree relatives of 80 patients were included, six with Crohn's disease, three with ulcerative colitis, and 30 healthy relatives, F/M: $25 / 14$, median age: 48 years (18-78).

\section{Ulcerative colitis}

Fifty two patients with ulcerative colitis were included, F/M: $34 / 18$, median age: $42 \cdot 2$ years (22-77), duration of disease $13 \cdot 3$ years $(0-53)$.

Seven of the patients had had a previous operation. Five $(71 \%)$ had had a total colectomy and two $(29 \%)$ a subtotal colectomy.

Relatives of patients with ulcerative colitis

Sixteen of the ulcerative colitis patients had familial occurrence of inflammatory bowel disease. Thirty four of 59 first degree relatives were included, eight with ulcerative colitis and 26 healthy relatives, F/M: 21/13, median age: 48 years (23-77).

\section{Controls}

Thirty one healthy controls were included, $\mathrm{F} / \mathrm{M}$ : $22 / 9$, age: 31 years $(22-63)$.

Crohn's disease activity index (CDAI) and ulcerative colitis scoring (UCS)

CDAI was measured in 42 patients, probands, and first degree relatives with Crohn's disease (seven had had an ileostomy and four failed blood samples), median score 76 (-13 to 401 ). Fifty six patients, probands, and first degree relatives with ulcerative colitis (five had had an ileostomy and two first degree relatives had not had a sigmoidoscopy) had UCS measured with a median score of II (I-IV). In total, 69 patients, 30 with Crohn's disease and 39 with ulcerative colitis, had inactive disease and 29 patients, 11 with Crohn's disease and 18 with ulcerative colitis had active disease ( $>150$ CDAI or $>$ II UCS).

\section{METHODS}

\section{PEG-400 permeation test}

PEG-400 (5.4 g) was dissolved in $19.8 \mathrm{~g}$ of water and $25 \mathrm{mg}$ methylparahydroxybenzoate and was ingested with a glass of water at $10 \mathrm{pm}$ after a three hour fast. The urine was then collected overnight for nine hours during continuous fasting. Alcohol was not permitted 24 hours before the test. The urine samples were collected and coded at Herlev University Hospital and mailed frozen to the laboratory in Irvine. PEG400 analysis of the urine was performed by HPLC (high performance liquid chromatography) according to the method of Delahunty et al. ${ }^{13}$ Permeation was expressed as a percentage of ingested PEG- 400 recovered in the urine.

\section{Inert sugar permeation test}

This test was carried out two days later in a similar manner. Lactulose $(11 \cdot 25 \mathrm{~g}), 1 \mathrm{~g}$ 1-rhamnose, and $1 \mathrm{~g}$ mannitol were dissolved in $95 \mathrm{~g}$ of water and preserved with $110 \mathrm{mg}$ methylparahydroxybenzoate and $1 \mathrm{~g}$ of alcohol. Because bacteriuria may invalidate the triple sugar test ${ }^{14}$ it was necessary to examine for this by urine culture or by urine tests for nitrite and leucocytes before the tests.

\section{Ratios of absorption test}

PEG/rhamnose, PEG/mannitol, lactulose/PEG, lactulose/rhamnose, and lactulose/mannitol ratios were calculated showing possible differences between permeation through epithelial cells (rhamnose and mannitol) and through tight junctions between epithelial cells (PEG and lactulose).

Permeability results in percentage urine excretion, median and range

\begin{tabular}{|c|c|c|c|c|c|c|}
\hline & $\begin{array}{l}\text { Crohn's } \\
\text { disease } \\
(n=53)\end{array}$ & $\begin{array}{l}\text { Ulcerative } \\
\text { colitist } \\
(n=53)\end{array}$ & $\begin{array}{l}\text { Healthy first } \\
\text { degree relatives } \\
(n=56)\end{array}$ & $\begin{array}{l}\text { Controls } \\
(n=31)\end{array}$ & $\begin{array}{l}C D \text { probands } \neq \\
+ \text { first degree } \\
\text { relatives } \\
(n=24)\end{array}$ & $\begin{array}{l}\text { UC probandsf } \\
+ \text { first degree } \\
\text { relatives } \\
(n=27)\end{array}$ \\
\hline PEG-400 & $\begin{array}{l}26 \cdot 44 \\
(10-76 \cdot 5)\end{array}$ & $\begin{array}{l}28 \cdot 44 \\
(0-55 \cdot 2)\end{array}$ & $\begin{array}{l}28 \cdot 37 \\
(0-36 \cdot 8)\end{array}$ & $\begin{array}{l}30.03 \\
(0-0.66)\end{array}$ & $\begin{array}{l}25 \cdot 48 \\
(10 \cdot 7-38 \cdot 4)\end{array}$ & $\begin{array}{l}30 \cdot 12 \\
\quad(14 \cdot 7-26 \cdot 2)\end{array}$ \\
\hline Lactulose & $\begin{array}{l}0 \cdot 140 \\
(0 \cdot 1-0 \cdot 2)\end{array}$ & $\begin{array}{c}0 \cdot 119 \\
(0-1 \cdot 03)\end{array}$ & $\begin{array}{c}0.186 \\
(0-0.58)\end{array}$ & $\begin{array}{c}0.145 \\
(0-0.57)\end{array}$ & $\begin{array}{l}0.185 \\
(0-0.75)\end{array}$ & $\begin{array}{l}0 \cdot 120 \\
(0-0.33)\end{array}$ \\
\hline Rhamnose & $\begin{array}{l}9.42 \\
(0-0.22)\end{array}$ & $\begin{array}{l}10 \cdot 22 \\
(0-20 \cdot 5)\end{array}$ & $\begin{array}{l}11 \cdot 61 \\
(0-24 \cdot 2)\end{array}$ & $\begin{array}{l}10 \cdot 03 \\
(4 \cdot 8-30)\end{array}$ & $\begin{array}{l}9 \cdot 47 \\
(1 \cdot 6-16 \cdot 6)\end{array}$ & $\begin{array}{l}11 \cdot 44 \\
(1 \cdot 6-18 \cdot 7)\end{array}$ \\
\hline Mannitol & $\begin{array}{l}26 \cdot 8 \\
(0-50 \cdot 5)\end{array}$ & $\begin{array}{l}26.9 \\
(0-65 \cdot 7)\end{array}$ & $\begin{array}{l}27 \cdot 2 \\
(0-64 \cdot 3)\end{array}$ & $\begin{array}{l}26 \cdot 1 \\
\quad(0 \cdot 2-89 \cdot 2)\end{array}$ & $\begin{array}{r}27 \cdot 3 \\
(0-48 \cdot 6)\end{array}$ & $26 \cdot 2$ \\
\hline PEG/rhamnose & $\begin{array}{l}2 \cdot 6 \\
(1 \cdot 2-19 \cdot 2)\end{array}$ & $\begin{array}{l}3 \cdot 1 \\
(1 \cdot 3-9 \cdot 1)\end{array}$ & $\begin{array}{l}2 \cdot 3 \\
(0.4-6 \cdot 4)\end{array}$ & $\begin{array}{l}2.9 \\
(0-8 \cdot 3)\end{array}$ & $\begin{array}{l}2 \cdot 6 \\
(1 \cdot 7-18 \cdot 8)\end{array}$ & $\begin{array}{l}2.9 \\
(1 \cdot 6-9 \cdot 1)\end{array}$ \\
\hline PEG/mannitol & $\begin{array}{l}0.95 \\
(0.4-5 \cdot 0)\end{array}$ & $\begin{array}{l}1 \cdot 2 \\
(0-3 \cdot 4)\end{array}$ & $\begin{array}{l}0.97 \\
(0.08-2 \cdot 7)\end{array}$ & $\begin{array}{l}1 \cdot 2 \\
(0-1 \cdot 4)\end{array}$ & $\begin{array}{l}0.86 \\
(0.5-1.97)\end{array}$ & $\begin{array}{l}1.03 \\
(0 \cdot 5-3 \cdot 4)\end{array}$ \\
\hline Lactulose/PEG & $\begin{array}{l}0.005 \\
(0-0.07)\end{array}$ & $\begin{array}{l}0.004 \\
(0-0 \cdot 19)\end{array}$ & $\begin{array}{l}0.007 \\
(0-0.01)\end{array}$ & $\begin{array}{l}0.005 \\
(0-0.03)\end{array}$ & $\begin{array}{l}0.006 \\
(0-0.02)\end{array}$ & $\begin{array}{l}0.004 \\
(0-0 \cdot 2)\end{array}$ \\
\hline Lactulose/rhamnose & $\begin{array}{l}0.016 \\
(0-0.113)\end{array}$ & $\begin{array}{l}0.0141 \\
(0-0.081)\end{array}$ & $\begin{array}{l}0.0146 \\
(0-0.046)\end{array}$ & $\begin{array}{c}0.0139 \\
(0-0.035)\end{array}$ & $\begin{array}{l}0.0208 \\
(0-0 \cdot 114)\end{array}$ & $\begin{array}{l}0.0109 \\
(0-0.016)\end{array}$ \\
\hline Lactulose/mannitol & $\begin{array}{c}0.0049 \\
(0-0.074)\end{array}$ & $\begin{array}{c}0.0048 \\
(0-0.030)\end{array}$ & $\begin{array}{c}0.0071 \\
(0-0.021)\end{array}$ & $\begin{array}{c}0.0054 \\
(0-0 \cdot 60)\end{array}$ & $\begin{array}{c}0.0057 \\
(0-0.031)\end{array}$ & $\begin{array}{c}0.0044 \\
(0-0.03)\end{array}$ \\
\hline
\end{tabular}

${ }^{\star} \mathrm{CD}=$ all Crohn's disease patients with/without familial occurrence and first degree $\mathrm{CD}$ relatives; $+\mathrm{UC}=$ all ulcerative colitis patients with without familial occurrence and first degree UC relatives; $¥ C D$ probands and their first degree inflammatory bowel disease relatives; §UC probands and their first degree inflammatory bowel disease relatives. 


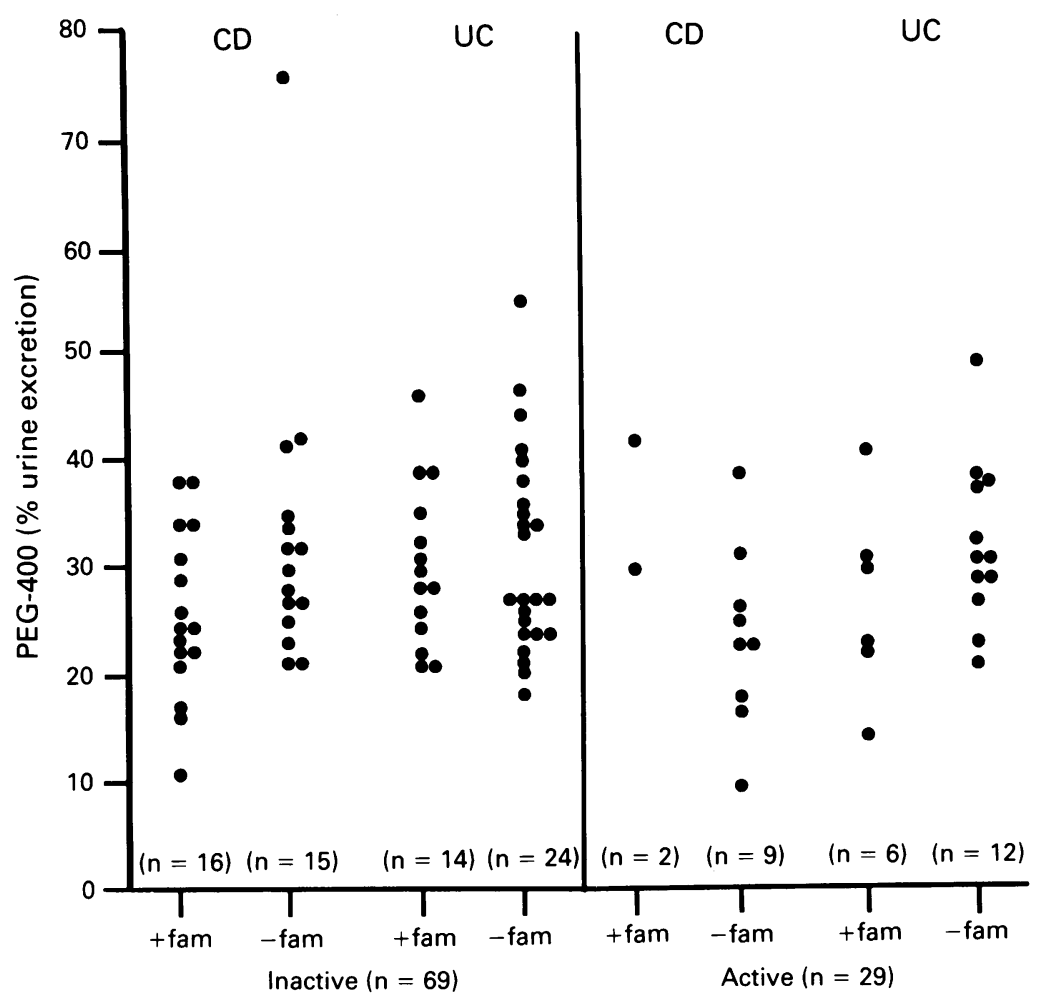

Figure 1: Urine excretion of polyethyleneglycol-400 (PEG-400) in patients, probands, and first degree relatives with inflammatory bowel disease according to inactive and active disease. $C D=$ Crohn's disease, $U C=$ ulcerative colitis, Fam = familial occurrence.

Figure 2: Correlation of Crohn's disease activity index (CDAI) and lactulose mannitol $(L / M)$ in Crohn's disease patients with and without familial occurrence.

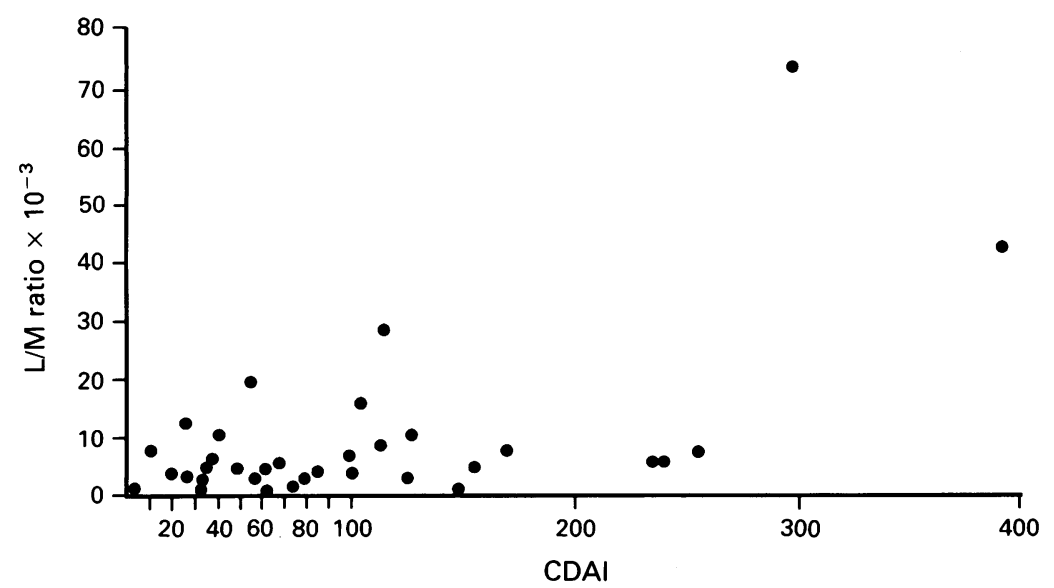

The Table shows the PEG-400 excretion results. A median of $28 \%$ of ingested PEG was excreted
Inflammatory bowel disease

Ethics

Informed consent was obtained from patients and relatives and the study was approved by the local ethical committees.

\section{STATISTICS}

Non-parametric methods were used for statistical analysis. Mann-Whitney's test for unpaired data was used for statistical analysis of the difference between the results of the groups studied. Kendall's T test was used for correlation analysis. A $5 \%$ value was chosen for statistical significance.

without significant differences between patients, relatives, and controls, and between patients with and without familial occurrence of inflammatory bowel disease.

In the Table the median values and ranges for urine excretion of lactulose, rhamnose, and mannitol are given as well as ratios between the different absorption tests. No differences were found between patients with and without familial occurrence, relatives, and controls.

The lactulose/rhamnose ratios, with a median of 0.015 did not differ between patients, relatives, and controls. A few patients and family members, however, had increased ratios but with no familial inter-relationship. These high $L / R$ values did not correlate with the disease activity either.

\section{Correlations}

Possible correlations between PEG, lactulose, rhamnose, mannitol, the different ratios of urine excretion and sex, age, disease duration, extent of disease and disease activity were analysed.

\section{Disease activity}

The PEG-400 excretion in patients with active disease, 11 Crohn's disease and 18 ulcerative colitis (CDAI >150 and UCS >II) did not differ from that of 69 patients without disease activity (CDAI $<150$ and UCS < = II) (Fig 1) and no correlation between PEG-400 absorption and numeric values of activity score in patients with active disease could be shown. The only positive correlation was found in Crohn's disease patients where the lactulose/mannitol ratio was positively correlated to CDAI $(p=0.01)$, however, the correlation coefficient was low: $z=+2 \cdot 5$ (Fig 2 ).

Age

A negative correlation $(z=-2 \cdot 5)$ between age and mannitol absorption was found in Crohn's disease patients $(p=0.03)$ but only a small part of the variation could be explained by age. There was a similar correlation in healthy relatives $(p=0.04)$. For ulcerative colitis patients the ratios $L / P E G, L / R, L / M$ showed negative correlations to actual patient age, $p=0.04, p=0.003$, and $p=0.03$ respectively.

\section{Disease duration}

Negative correlation between duration of disease and PEG/rhamnose in ulcerative colitis patients was found, $p=0.03$.

No other statistically significant correlations could be found.

\section{Discussion}

The intestinal epithelium is an external surface of the body, which comes into contact with a wide variety of potentially harmful compounds and organisms. These agents include bacteria and bacterially synthesised products, food antigens, and ingested chemicals and toxins. Thus, the intestinal epithelium has to form a barrier to prevent the absorption of these potentially harm- 
ful agents and avert their penetration into the systemic circulation. The barrier protective function of the intestine is often referred to as intestinal permeability.

There has been a great deal of interest in the possibility that intestinal permeability may be increased in patients with Crohn's disease and their first degree relatives. Several studies have shown that intestinal permeability is increased in patients with Crohn's disease. These studies have used a variety of marker compounds such as lactulose, ${ }^{51} \mathrm{Cr}$-EDTA, mannitol, and rhamnose. PEG-400 permeation, however, has been reported most frequently as decreased ${ }^{15}$ but also normal, ${ }^{17}$ and increased. ${ }^{51617}$ To differentiate between permeability changes secondary to the inflammation $v$ permeability changes that may be of aetiological significance, some studies have looked at the intestinal permeability of relatives of patients with Crohn's disease..$^{5-7} 18$ The results have been conflicting, but the idea of a genetically transmitted increased permeability offers an attractive aetiological explanation that lead to this large study of families with known clustering of inflammatory bowel disease among its members. Because the first and often cited study was performed by Hollander et $a l^{5}$ our study was carried out in collaboration with that group, who analysed the blinded urine samples from the patients, relatives, and controls according to their routine.

In the overall analysis of the results no statistically significant differences in intestinal permeability were found between patients with Crohn's disease, healthy or diseased relatives, and the control group of patients with ulcerative colitis and healthy controls. These conclusions are valid both when expressing the results as permeation of the individual four probes and when expressing the results as ratios between the different probes (Table). Although the oral permeability studies reflect small intestinal and not colonic permeability, we found the ulcerative colitis group with relatives relevant to study because even here a possible increased permeability could be of aetiological significance. The hypothesis of 'genetic leakiness' in inflammatory bowel disease could thus not be confirmed.

Similar results were obtained with the ${ }^{51} \mathrm{Cr}$ EDTA permeation test. ${ }^{18}$ Recently ${ }^{67}$ two studies similar in design to ours but not including inflammatory bowel diseased relatives showed no increase in PEG-400 in healthy relatives, and the $25 \%$ median excretion found was within our range. In another study, however, $33 \%$ of the Crohn's disease relatives were found to have increased $L / M$ ratio compared with healthy relatives. ${ }^{9}$ Healthy relatives compared with Crohn's disease patients has recently been found significantly more sensitive to NSAIDs than healthy controls, measured by increased L/M ratio. ${ }^{10}$

In contrast with most studies our study minimises the risk of type 2 error because the number of participants $(n=203)$ is fairly large, whereas previous studies have tested smaller numbers of patients. There are numerous factors that may influence permeation, resulting in either an increase or decrease in permeation. These factors could therefore influence the conclusions of small studies. The factors that could increase intestinal permeability include the ingestion of spicy Indian meals, ${ }^{19}$ NSAID use, ${ }^{20}$ infectious gastroenteritis, ${ }^{21}$ chemotherapy, ${ }^{22}$ and marathon running. ${ }^{23}$ In contrast, smoking has recently been shown to decrease the permeability of the gut in healthy persons when measured by ${ }^{51} \mathrm{Cr}$ EDTA. ${ }^{24}$ Steroids have been shown to tighten the gut in active Crohn's disease after eight weeks of treatment. ${ }^{25}$ Elemental diet reduced the lactulose/mannitol permeation in the intestine in active Crohn's disease ${ }^{26}$; however, another study failed to show any change in permeation of ${ }^{51} \mathrm{Cr}$ EDTA in moderately active Crohn's disease patients after two weeks treatment with elemental diet. ${ }^{27}$

A possible explanation of the difference between our results on lactulose permeation and previous studies ${ }^{28-31}$ could be the mild nature of the disease activity in our Crohn's disease patients. Seventy five per cent had a CDAI index of less than 150 and most of our patients were not receiving drugs such as corticosteroids or immunosuppressive agents. We found, however, a slightly positive correlation between the activity of the disease and the permeation of lactulose-mannitol ratio (Fig 2).

In conclusion, the previously reported results of increased PEG-400 permeation in Crohn's disease patients and their first degree healthy relatives could not be confirmed because even in families with clustering of inflammatory bowel disease patients no increase in permeation could be shown. Thus the hypothesis of a 'genetic leakiness' of the intestine was not confirmed.

This work was supported by grants from Aage Louis-Hansens Mindefond and the Goldsmith Family Foundation, Los Angeles.

1 McConnell RB. Genetics of inflammatory bowel disease. In: Allan RB, Keighley MR, Alexander-Williams J, Hawkins C,
eds. Inflammatory bowel diseases. Edinburgh: Churchill eds. Inflammatory bowel

2 Mendeloff $\mathrm{A}$. The epidemiology of idiopathic inflammatory bowel disease. In: Kirsner JB, Shorter RG, eds. Inflammatory bowel disease. Philadelphia: Lea and Febiger, 1980: 522.

3 Elmgreen J, Both H, Binder V. Familial occurrence of complement dysfunction in Crohn's disease: correlation with intestinal symptoms and hypercatabolism of complement. Gut 1985; 26: 151-7.

4 Orholm M, Munkholm P, Langholz E, Nielsen OH, Sørensen TIA, Binder V. Familial occurrence of inflammatory bowel disease. N Engl F Med 1991; 324: 84-8.

5 Hollander D, Vadheim CM, Brettholz E, Petersen G, Delahunty T, Rotter J. Increased intestinal permeability in patients with Crohn's disease and their relatives. Ann Intern patients with Crohn's $1986 ; 105: 883-5$.

6 Theahon K, Smethurst P, Levi AJ, Menzies IS, Bjarnason I. Intestinal permeability in patients with Crohn's disease and their first degree relatives. Gut 1992; 33: 320-3.

7 Ruttenberg D, Young GO, Wright JP, Isaacs S. PEG-400 excretion in patients with Crohn's disease, their first-degree relatives, and healthy volunteers. Dig Dis Sci 1992; 37: $705-8$.

8 Katz KD, Hollander D, Vadheim CM, McElree, Delahunthy $\mathrm{T}$, et al. Intestinal permeability in patients with Crohn's disease and their healthy relatives. Gastroenterology 1989; 97: 927-31.

9 May GR, Sutherland LR, Meddings JB. Lactulose/Mannitol permeability is increased in relatives of patients with Crohn's disease. Gastroenterology 1992; 102: A934.

10 Pironi L, Miglioli M, Ruggeri E, Dallsata MA, Ornigotti L, Valpiani D, et al. Effect of non-steroidal anti-inflammatory drugs (NSAID) on intestinal permeability in first degree relatives of patients with Crohn's disease. Gastroenterology 1992; 102: A697.

11 Best WR, Becktel JM, Singleton JW, Kern F Jr. Development of Crohn's disease activity index. National Cooperative Crohn's Disease Study. Gastroenterology 1976; 70: 439-44.

12 Binder V. A comparison between clinical state, macroscopic and microscopic appearances of rectal mucosa, and cytologic picture of mucosal exudate in ulcerative colitis. Scand 7 Gastroenterol 1970; 5: 627-32.

13 Delahunty T, Hollander D. New liquid-chromatographic method for measuring polyethylene glycol in urine. Clin Chem 1986; 32: 351-3. 
14 Milnes JP, Walters AJ, Andrews DJ, Low-Beer TS. Urinary infection may invalidate the double-sugar test of intestinal permeability. Scand F Gastroenterol 1988; 23: 885-90.

15 Olaison G, Sjödahl R, Tagesson C. Abnormal intestinal permeability in Crohn's disease. A possible pathogenic factor. Scand $\mathcal{F}$ Gastroenterol 1990; 25: 321-8.

16 Olaison G, Leandersson P, Sjödahl R, Tagesson C. Intestinal permeability to polyethyleneglycol 600 in Crohn's disease. Peroperative determination in a defined segment of the small intestine. Gut 1988; 29: 196-9.

17 Olaison G, Sjödahl R, Leandersson P, Tagesson C. Abnormal intestinal permeability pattern in colonic Crohn's disease. Absorption of low molecular weight polyethylene glycols Absorption of low molecular weight polyethylene glycols
after oral or colonic load. Scand f Gastroenterol 1989; 24: after oral $571-6$.

18 Ainsworth M, Eriksen J, Rasmussen JW, Schaffalitsky De Muckadell OB. Intestinal permeability of ${ }^{51} \mathrm{Cr}$-labeled ethylenediaminetetraacetic acid in patients with Crohn's disease and their healthy relatives. Scand $\mathcal{F}$ Gastroenterol 1989; 24: 993-8.

19 Bjarnason I, Levi S, Smethurst P, Menzies IS, Levi AJ Vindaloo and you. $B M 7$ 1988; 297: 24-31

20 Bjarnason I, Williams P, So A, Zanelli GD, Levi AJ, Gumpel $\mathrm{JM}$, et al. Intestinal permeability and inflammation in rheumatoid arthritis: effects of non-steroidal antiinflammatory drugs. Lancet 1984; i: 1171-4.

21 Isolauri E, Juntunen M, Wiren S, Vuorinen P, Koivula T. Intestinal permeability changes in acute gastroenteritis: effects of clinical factors and nutritional management. effects of clinical factors and nutritional
$\mathcal{F}$ Pediatr Gastroenterol Nutr 1989; 8: 466-73.

22 Fegan C, Poynton CH, Whittaker JA. The gut mucosal barrier in bone marrow transplantation. Bone Marrow Transplant 1990; 5: 373-7.

$23 \emptyset$ ktedalen O, Lunde OC, Opstad PK, Aabakken L, Kvernebo $\mathrm{K}$. Changes in the gastrointestinal mucosa after longdistance running. Scand f Gastroenterol 1992; $27: 270-4$.

24 Prytz H, Benoni C, Tageson C. Does smoking tighten the gut? Scand F Gastroenterol 1989; 24: 1084-8.

25 Wyatt J, Vogelsang H, Lochs H. Effect of corticosteroids on intestinal permeability in patients with active Crohn's disease Gastroenterology 1992;102: A947.

26 Sanderson R, Boulton P, Menzies I, Walker-Smith JA. Improvement of abnormal lactulose/rhamnose permeability in active Crohn's disease of the small bowel by an elemental in active Crohn's disease of
diet. Gut 1987; 28: 1073-6.

27 Munkholm Larsen P, Rasmussen D, Rønn B, Elmgren J, Munck O, Binder V. Elemental diet - a therapeutic Munck O, Binder V. Elemental diet - a therapeutic
approach in treatment of ulcerative colitis and Crohn's approach in treatment of ulcerative

28 Andre F, Andre C, Emery Y, Forichon J, Descos L, Minaire Y. Assessment of the lactulose-mannitol test in Crohn's disease. Gut 1988; 29: 511-5.

29 Pearson ADJ, Eastham EJ, Laker MF, Craft AW, Nelson B. Intestinal permeability in children with Crohn's disease and coeliac disease. BMF 1982; 285: 20-1.

30 Ukabam SO, Clamp JR, Cooper BT. Abnormal small intestinal permeability to sugars in patients with Crohn's disease of the terminal ileum and colon. Digestion 1983; 27: $70-4$.

31 Incà RD, Di Leo V, Martines D, Mancin O, Lecis PE, Giacon $\mathrm{G}$, et al. Permeability to sugars can be helpful in predicting disease activity. Gastroenterology 1992; 102: A616. 